\title{
Review of digital technologies in agriculture as a factor that removes the growth limits to human civilization
}

\author{
Alexander Bogomolov ${ }^{1}$, Victor Nevezhin ${ }^{1, *}$, Margarita Larionova $^{1}$, and Elena Piskun ${ }^{2}$ \\ ${ }^{1}$ Financial University under the Government of the Russian Federation, 49 Leningradsky Prospect, 25993, Moscow, Russia \\ ${ }^{2}$ Sevastopol State University, 33 ul. University, 299053, Sevastopol, Russia
}

\begin{abstract}
According to Meadows' model, the main factor that determines the limits to the growth of the human civilization is the agricultural sector of the planet, the latter, however, significantly pollutes the environment and togather with other factors contributes much to global warming. A half of all the habitable land is used for agriculture. Unless the efficiency of agriculture is fundamentally improved and the amount of waste generated as a result, is reduced, a global catastrophe may befall in 30-50 years. Whereas agrarian "garbage" may not be just the waste that pollutes the environment, it can decrease the burden on the environment by being the raw material for fertilizers, feed or fuel manufacturing. Modern digital technologies can improve the efficiency of agriculture, organize low-waste or non-waste production and that will enable people to diminish the pollution of the environment and push away the limits to the growth of human civilization. The developed countries are using digital technologies more and more intensively to increase agricultural productivity and, at the same time, reduce both environmental pollution with agricultural waste and disruption of the ecological balance. The digitalization of agricultural business, the use of geoinformation technologies, drones, robots, artificial intelligence and other technologies of the digital society help to push the limits to the growth of human civilization away into the future.
\end{abstract}

\section{Introduction}

The growth model of human civilization was developed by the Club of Rome in the late 60s. Their task was to investigate the immediate and distant consequences of large-scale decisions related to the paths of development chosen by mankind. It was proposed to use a systematic approach to study global problems, using the method of mathematical computer modeling. The results of the study were published in 1972 in the first report to the Club of Rome entitled "The Limits to Growth" [1,2].

The authors of the report concluded that if the current trends in population growth, industrialization, environmental pollution, food production and resource depletion continue, then over the next century the world will come to the limits of growth, there will be an unexpected and uncontrollable decline in population and production volume.

The model they built, like any other, proved out to be imperfect, oversimplified and incomplete so later they repeatedly tried to update and improve it. Nevertheless, it would be wrong to ignore their findings, since the problems identified by the model are obvious and acute. Two years ago, an international group of scientists published a study in Nature Sustainability journal, where they claimed that the Earth is capable of supporting no more than 7 billion people at the subsistence level. There are almost 7.8 billion people now on Earth (a year ago there were 7.7). And according to UN forecasts, by 2030 there will be 8.5 billion, by $2050-9.7$ billion, and by 2100 - there will be the number that the authors of the "Limits to Growth" report warned about - 11.2 billion people.

The authors of the study believed that it is possible to change the trajectory of civilization development and come to sustainable economic and environmental stability in the long term. Technological progress will allow to replace harmful industries with environmentally friendly ones (which will reduce the load on the natural ecosystem) and increase agricultural productivity, while medicine and social transformations will help to avoid a demographic crisis and social shocks.

Technological progress, which is manifested primarily in digitalization and informatization of all spheres of society, allows for the conclusion that humanity has entered a new phase of its development, the one which is called the information-oriented or digital society [3].

At this stage of its development, mankind is able to solve the problem of environmental pollution with the waste of agricultural production by increasing its efficiency and processing waste into useful products.

Also, the development of food production technologies can lead, as the outstanding Russian scientist Vladimir Vernadsky believed, to the discovery of new forms of plants and animals with desired characteristics, as well as to the production of artificial food made by artificial photosynthesis. At this stage, a

\footnotetext{
* Corresponding author: VPNevezhin@,fa.ru
} 
person will be able to control climate change and use all types of renewable energy sources.

The aim of the study is to review the main digital technologies used in agriculture, which contribute to an increase in its efficiency and a decrease in its burden on the environment.

\section{Current state and development trends of the agricultural sector of the economy}

Agricultural development is usually accompanied by environmental pollution from animal waste, chemicals used in the cultivation of crops, depletion of mail, etc., which has a noticeable impact on the rural environment in particular and on the global environment in general. Many studies and publications are devoted to these problems in both domestic and foreign literature (see, for example, [4-8].

Reducing the scale of environmental pollution with agricultural waste and restoring ecological balance requires improving agricultural management and the use of advanced waste-free technologies [5, 6, 7]. One of the main directions for solving this problem can be the digitalization of the economy in general and agriculture in particular [ 9].

The main types of pollution are as follows:

1. Pesticides and their decay products. Every year, farmers around the world use more than 1 million tons of pesticides and the scale of their use is constantly growing. Almost any field that is actively treated with pesticides is a source of their spread for several kilometers around due to groundwater, into which chemistry infiltrates.

2. Heavy metals. Low-quality phosphorus and other synthetic fertilizers may contain a certain amount of heavy metals, in particular cobalt, cadmium, zinc and others.

3. Nitrates. Their source is nitrate, which is actively used as a fertilizer and a plant growth stimulant.

4. Waste water from livestock complexes. Agricultural soil pollution is not limited to agrochemistry. Livestock complexes are also making their contribution.

All these causes of environmental pollution require research and introduction of certain technologies, which have digital and information technologies as the key components $[10,11]$.

For a long time, agriculture has not been a business attractive to investors. This was due to a long production cycle, which is subject to natural hazards and to possible high yield losses during cultivation, collection and storage, as well as the inability to automate biological processes, and a lack of progress in productivity and innovation. The use of IT technologies in agriculture was limited to the use of computers and software, mainly for financial management and tracking commercial transactions. Recently farmers began to use digital technologies for monitoring agricultural crops, poultry and cattle breeding and other areas of the agricultural process.
The introduction of modern digital information technologies into agricultural production is progressing at an increasing pace [12-15]. Obtaining data on certain forecasts of weather may be available to farmers throughout the day. And this not only makes it possible to more efficiently and effectively use various chemical plant protection products, but also to significantly reduce the risk of environmental pollution. One of the most promising ways to improve the efficiency of agricultural production management is the use of information systems based on geographic information systems (GIS). Such systems may help farmers with the following issues:

- information support for decision making;

- planning of agrotechnical operations;

- monitoring of agrotechnical operations and the state of crops;

- forecasting crop yields and assessing losses;

- planning, monitoring and analysis of the use of technology.

GIS will also help to improve the processes in the livestock sector, for example, to efficiently and costeffectively solve the task of mapping different kinds of areas such as the following:

- areas with scares natural vegetation;

- desertification due to the overload of pasture fields;

- degradation of natural vegetation in pasture fields;

- areas with depleted vegetation and erosion of the soil cover around the watering sites, on the tracks, etc.;

- areas with polluted drains generated by livestock complexes and poultry farms, etc.

It should be noted that on average less than $70 \%$ of the generated waste is used as fertilizers, the rest goes to storage ponds and surrounding arias, infiltrating water reservoirs and underground waters.

Automated workstation of an agronomist with the help of GIS technologies can:

- keep records of fields differentiating them according to the amount of yields, types of crops, applied fertilizers and protection products;

- help plan fertilization taking into account the individual characteristics of the fields;

- provide information support in assessing the quality of work and planning the workload;

Due to combining agricultural facilities into a single network, the exchange and management of data based on the Internet, the increased productivity of computers, the development of software and cloud platforms, it became possible to automate the maximum number of agricultural processes by creating a virtual (digital) model of the entire production cycle and interconnected chain links. These enabled farmers to plan the work schedule with mathematical precision as well as to take emergency measures to prevent losses in due time and to calculate the possible yield, production costs and profit.

"Robotization" of production is especially relevant for large farms. Flying over fields drones use cameras and sensors, which allows farmers to see in real time what each plant looks like, how crops mature and how the soil color changes. 
"Agricultural" drones allow to create electronic maps of fields in 3D format, calculate the Normalized Difference Vegetation Index (normalized vegetation index) in order to effectively fertilize crops, inventory the work being done and protect farmland.

According to the PWC analytical agency, in a few decades, the market for "agricultural" drones (excluding aircraft-type drones) may amount to about \$ 32.4 billion. This growth will be due to an increase in the global population - if the goal is to feed everyone, innovations have to be introduced in the agricultural sector, and that will allow to ripe richer crops.

Nowadays the countries which make a heavy use of "agricultural" drones are the USA, China, Japan, Brazil, EU countries and others. The largest players in the world UAV market are AeroVironment Inc, AgEagle, DJI, Yamaha and others [12].

Goldman Sachs predicts that the agribusiness sector will become the second-largest drone using sector by 2021. According to Gartner researchers, the increase in UAVs against 2016 amounts to $30 \%$, in total value 7\% of which fell on agribusiness.

At the end of December 2017, DJI Innovation Technology (DJI), China's largest commercial drone manufacturer, reported that more than 10,000 UAV operators are using DJI's MG-series drones for agricultural purposes. According to the company, sales of such drones in 2020 will reach 45 thousand units. Due to the modernization of agriculture in the PRC, the market for advanced devices for farmers is experiencing a significant rise. In 2023, the use of drones in China's agro-industrial complex is expected to grow by $40 \%$, and sales of such devices in monetary terms will make for 16 billion yuan ( $\$ 2.4$ billion).

There have been an interesting project of one UK company, their goal is to automate all processes of crops growing. At Hand Free Hectare farm [16] farmers just observed the growth of agricultural crops without doing anything themselves. As a result, autonomous modified tractors and drones have grown 4.5 tons of barley on an area of 2.5 hectares. People have automated everything from sowing seeds to harvesting. The machines were operated by technical staff from the control room. Drones with built-in multispectral sensors were surveying the land. Small agricultural machines took samples of the land, analyzed it and selected the needed mineral fertilizers. Cameras in real time informed about pests or weeds.

Advanced technologies are also coming to livestock farming. In November 2017 the Internet of Things (IoT) system was developed in the United States. The system makes it possible to monitor remotely the health status of livestock in pig farms. The solution involves attaching special tags to the pig's ears. Using a variety of sensors, they monitor the body temperature and movement of animals to assess their well-being and readiness for breeding. The information from the sensors is transferred to the cloud, where it is analyzed, and then the processed information is sent back to the pig farm employees.

With the increase in the world's population, agricultural areas per capita are rapidly decreasing. Forecasts made by the Food and Agriculture
Organization of the United Nations (FAO) [17] show that in order to feed the global population, farmers will need to consistently produce nearly 1.5 times more harvest by 2050. To meet this condition, agricultural complexes will need environmentally friendly crop protection products and other technical innovations [18]. To make this true, Bosch and Baye announced in September 2017 that they were going to team up. Through a three-year research partnership, the companies will develop smart spraying technology that will make the use of pesticides more efficient. Using cameras with special sensors, the new smart spraying technology differentiates weeds from crops. Then a special pesticide pollination method is applied, thus, only the weeds are treated, and that significantly reduces the damage to the environment.

Methods and models with elements of artificial intelligence and machine learning are increasingly used in the fight against environmental pollution with agricultural waste [19-23].

Improving the environment on the basis of rationalizing agricultural production is only a part of the solution to the problem of zero waste in the agroindustrial complex. To solve the environmental problems caused by the accumulation of organic agricultural waste, methods and technologies for their processing should also be developed and widely used. Biotechnology proved to have the most effective processing methods $[24,25]$.

The processing of agricultural waste with their further use, for example, in the food industry, is one of the most complex studies in the field of biotechnology- it seems rather difficult in terms of technical implementation. For example, in the wine industry, the annual accumulation of a huge amount of waste from the operation of vineyards and wineries causes serious damage to the environment. Nevertheless, biotechnology can solve this problem. Improving and reducing the cost of biotechnology will contribute to solving the problems of waste processing in other agricultural industries, for example, in cattle breeding, growing mushrooms etc.

\section{Results and discussions}

Financial group Goldman Sachs ${ }^{\mathrm{a}}$ notes that the global agricultural industry has entered the "digital era" and the use of new generation technologies can increase its productivity by $70 \%$ by 2050 . Experts estimate that application of Internet technologies alone can give a significant increase in yields, the one that the mankind has not seen even during the time when tractors, herbicides and genetically modified seeds were fist invented.

Technologies evolved, became cheaper and advanced to such a level that for the first time in the history of the industry it became possible to obtain data on each

\footnotetext{
${ }^{a}$ Goldman Sachs Group - Is one of the world's largest investment banks and a financial conglomerate. Founded in 1869 and located in New York, known as "The Firm" among financial experts.
} 
agricultural facility and its surroundings, to calculate mathematically accurately the algorithm of actions and predict the result.

It has long been believed that digital technology is environmentally friendly. However, as more and more new facts appeared, this assessment changed to the opposite.

The report issued in December 2017 by the French Agency for Environmental Protection and Energy Efficiency confirmed that the intensive use of information technologies has a serious impact on carbon dioxide emissions. It turned out, for example, that sending one e-mail requires as much electricity as is needed to ensure the continuous operation of an ordinary light bulb for 24 hours [23].

Here are some examples of human influence on the environment:

1. The problem of overpopulation - every hour in the world there are born 9 thousand people more. Humanity does not cease to increase the production of material goods, and the increase in cheap production has a very bad effect on the environment - polluting rivers, poisoning the air, and sometimes it may lead to more serious consequences in the form of environmental problems.

2. Work on the computer - electromagnetic field; ultraviolet, infrared and x-ray radiation; the materials from which the computer is made, all of these can release various chemical compounds.

Biotechnologies used in agriculture can have a significant impact on its efficiency and reduce the impact of hazardous waste on the environment.

Biotechnology, in the form of genetic engineering, is one aspect of science that has the potential to provide important benefits when used carefully and ethically. Society must have a balanced understanding of the fundamentals of biotechnology and genetic engineering, the processes used to create transgenic organisms, the types of genetic material used, the benefits and risks of new technology.

\section{Conclusions}

Having analyzed the positive and negative factors of the impact of digital technologies on the environment, we can conclude that the created ecological systems and technologies reduce the man-made load on the environment. Modern technology and equipment allow the rational use of resources and improve the state of the planet.

On April 12, 2020, the Government of the Russian Federation approved the "Strategy for the Development of the Agroindustrial and Fisheries Complexes of the Russian Federation for the Period up to 2030" (hereinafter referred to as the Strategy), based on modern technology and staffed with highly qualified personnel (national goal N 9) "[29].

The State Program "Digital Economy of the Russian Federation" (approved on June 4, 2019) also includes many activities, such as the construction of "serious infrastructure" in agricultural areas. According to statistics, $20 \%$ of such territories in Russia have $3 \mathrm{G}$. This is catastrophically small, while in many territories there is no communication at all [30].

To improve the efficiency of agricultural production and reduce its waste, it is necessary to provide all local agricultural departments with high-quality Internet access, as well as a high-quality signal for combines, tractors and other equipment. Therefore, the Ministry of Agriculture offered the government an "ambitious task" together with the Ministry of Industry and Trade, the Ministry of Telecom and Mass Communications, Rostelecom and others to provide a good coverage of agricultural land, if possible, $5 \mathrm{G}$.

A drastic shortage of qualified personnel is one of a few worth mentioning problems in the field of applied digital technologies in the agro-industrial complex of Russia. Another problem is dependence on imported technologies: about $95 \%$ of technologies in Russian agriculture are foreign $[25,26]$.

The implementation of the Program first requires an audit of what is already there. An analytical center was created at the Ministry of Agriculture, which the department considers as a base for collecting those technologies that work effectively, and promoting these technologies in the industry, training specialists and much more.

Agricultural biotechnology has the potential to improve crop productivity and food security at the global level. At the same time, there is growing concern about genetically engineered crops and their environmental impact in the food chain. Whereas the introduction of such technologies has its consequences, there is a need to establish biosafety regulatory systems to reduce and eliminate the potential risks posed by agricultural biotechnology to flora and fauna.

The world's best practices in creating effective technologies for managing agricultural production and processing waste polluting the environment should be studied and applied in Russia, taking into account our own experience in the implementation of large-scale projects and specifics. The tendency to increase the burden on the planet's ecology from agricultural production is to be stopped. It might be achieved by increasing the efficiency of agricultural production through digital technologies and biotechnology, thus pushing away the limits to the growth of human civilization.

\section{References}

1. D.H. Meadows, J. Randers, D.L. Meadows, W.W. Behrens. The Limits to Growth: A Report for the Club of Rome's Project on the Predicament of Mankind. NY, Universe Books. 211 P. (1972). ISBN 0876631650.

2. D.H. Meadows etc. The limits to growth. 30 years later: A study guide. 3rd ed. 342 P. (2007). ISBN 978-5-94628-218-5.

3. Digital society and the information age. URL: https://www.futurelearn.com/info/courses/digitalsociety/0/steps/23808/ (Access date: 10.02.2021) 
4. How do agricultural wastes harm the environment? https://www.quora.com/How-do-agriculturalwastes-harm-the-environment. (Access date: 10.03.2021)

5. A.E. Bolgov. The impact of the agro-industrial complex on the environment. The successes of modern natural science. No. 2. - p. 95-96. (2004).

6. S.R. Bayramukova, V.Yu. Mesharova. The impact of enterprises of the agro-industrial complex on the environment. file: /// C: /Users/8523 1/AppData/Local/Temp/vozdeystviepredpriyatiy-agropromyshlennogo-kompleksa-naokruzhayuschuyu-sredu.pdf

7. I. Novitsky/ Agricultural pollution of the environment. https: //selkhozportal.rf/articles/selskohozyajstvennoezagryaznenie-okruzhayushhej-sredy (Access date: 10.03.2021)/

8. Impact of agriculture on the environment. https://www.polnaja-jenciklopedija.ru/planetazemlya/vozdeystvie-selskogo-hozyaystva-naokruzhayuschuyu-sredu.html. (Access date: 10.03.2021)

9. Digital Society. https://ibreresearchgroup.org/ en/a/digital-society. (Access date: 12.03.2021)

10. A.F. MacKenzie, M.X Fan, F. Cadrin. Nitrous Oxide Emission in Three Years as Affected by Tillage, Corn-Soybean-Alfalfa Rotations, and Nitrogen Fertilization. Journal of Environmental Quality. 27(3), pp. 698-703. (1998). DOI:10.2134/jeq1998.00472425002700030029x

11. A.G. Chuvakhova, T.V. Karpenko. Digital technologies and their impact on the environment. (2020).

URL: https://scienceforum.ru/2020/article/2018023052. (Access date: 10.02.2021)

12. A.V. Keshelava V.G. Budanov, V.Yu. Rumyantsev etc. Introduction to the Digital Economy: On the Threshold of the Digital Future. V.1, Monograph. M. 44 p. (2017).

13. E. Montesinos. Development, registration and commercialization of microbial pesticides for plant protection. International Microbiology. 6(4), pp. 245-252. (2003). DOI:10.1007/s10123-003-0144-x.

14. Agricultural waste concept, generation utilization and management. Nigerian Journal of Technology. 35(4), pp. 957-964. (2016). DOI: $10.4314 /$ njt.v35i4.34

15. An overview of digital technologies for the agroindustrial complex: from GIS to the Internet of things. (2020). URL: https://integralrussia.ru/2020/07/30/tsifrovaya-platforma-razvitiyaagropromyshlennogo-kompleksa-kontseptsiya-iosnovnye-tezisy. (Access date: 12.02.2021)

16. Hands Free Hectare HFH. https://www.youtube.com/channel/UC7. (Access date: 10.02 .2021 )
17. N.M. Trendov, S. Varas and M. Zeng. Digital technologies in agriculture and rural areas. Food and Agriculture Organization of the United Nations. Rome. (2019).

http://www.fao.org/3/ca4985en/ca4985en.pdf.

(Access date: 15.02.2021)

18. E.P. Gusakova, A.V. Shchutskaya, E.P. Afanaseva. Digital Technologies as a Tool for Solving Basic Industrial Problems in the Agro-Industrial Complex. Digital Age: Chances, Challenges and Future. (2020). DOI: 10.1007/978-3-030-27015-5_22.

19. A. Kamilaris1 and F.X. Prenafeta-Boldú. Deep Learning in Agriculture: A Survey. Institute for Food and Agricultural Research and Technology (IRTA).

https://arxiv.org/ftp/arxiv/papers/1807/1807.11809.p df. (Access date: 14.02.2021)

20. X. Song, G. Zhang, F. Liu, D. Li, Y. Zhao \& J. Yang, J. Modeling spatio-temporal distribution of soil moisture by deep learning-based cellular automata model. Journal of Arid Land, 8(5), pp. 734-748. (2016).

21. C. Potena, D. Nardi \& A. Pretto. Fast and accurate crop and weed identification with summarized train sets for precision agriculture. International Conference on Intelligent Autonomous Systems. Shanghai, China: Springer, Cham, pp. 105-121. (2016).

22. S. Liaghat \& S.K. Balasundram. A review: The role of remote sensing in precision agriculture. American journal of agricultural and biological sciences, 5(1), pp. 50-55. (2010).

23. N. Kussul, M. Lavreniuk, S. Skakun \& A. Shelestov. Deep Learning Classification of Land Cover and Crop Types Using Remote Sensing Data. IEEE Geoscience and Remote Sensing Letters. 14(5), pp. 778-782. (2017).

24. M. Petre, A. Teodorescu. Biotechnology of Agricultural Wastes Recycling Through Controlled Cultivation of Mushrooms. (2012). DOI: $10.5772 / 29998$

25. Investigating the Environmental Effects of Agriculture Practices on Natural Resources. USGS. (2007),

URL: https://pubs.usgs.gov/fs/2007/3001/pdf/508FS2007_ 3001.pdf. (Access date: 10.02.2021)

26. S. Mittal \& M. Mehar. How mobile phones contribute to growth of small farmers? evidence from India. Quarterly Journal of International Agriculture. 51(3), pp. 227-244. (2012).

27. Program Digital Economy of the Russian Federation.

http://static.government.ru/media/files/9gFM4FHj4P sB79I5v7yLVuPgu4bvR7M0.pdf. (Access date: 10.02.2021)

28. N. Orlova. Digital technologies in the agrifoodsector: key challenges in Russia. Forum 2020 "Digital transformation-towards sustainable food value chains in Eurasia". (2020). 
https://inagres.hse.ru/data/2020/06/26/1607079859/I

AMO_Orlova.pdf. (Access date: 10.02.2021)

29. Development strategy of the agro-industrial and fishery complexes of the Russian Federation for the period up to 2030. http://docs.cntd.ru/document/564654448. (Access date: 20.02.2021)

30. M.V. Tiranova. Errors in the principles of the formation of the environmental policy of the Russian Federation. Modern science: actual problems of theory and practice. Series: Economics and Law. No 5, pp. 39-41. (2017). 